\title{
Comparative efficiency of switched reluctance and induction motor drives for slowly varying loads
}

\author{
P. Andrada, B. Blanqué, J.I. Perat, M. Torrent, E. Martínez, J. A. Sánchez \\ GAECE, Grup d'accionaments elèctrics amb commutació electrònica \\ Departament d'Enginyeria Elèctrica UPC-EPS d'Enginyeria de Vilanova i la Geltrú \\ Avinguda Victor Balaguer sn, 08800 Vilanova i la Geltrú \\ Phone: +34 93 8967732; Fax: +34 938967700 \\ Andrada@ee.upc.edu
}

\begin{abstract}
A current-controlled switched reluctance motor drive for variable speed applications with efficiency optimization is presented. Firing angles are computed online, the turnon is calculated by means of the rule of Bose, and the turn-off is calculated using the general theory of the optimal turn-off angle proposed by Gribble. In steady state operation, the initial selection of firing angles is fine-tuned by means of an algorithm that minimizes the input power of the drive. An efficiency and electrical energy consumption comparison with a commercial vector-controlled induction motor drive of the same size is also included. Experimental results show that the proposed switched reluctance motor drive is a good choice for applications that require slow varying loads and energy savings.
\end{abstract}

\section{Key words}

Switched reluctance drive, variable speed drive, efficiency, induction motor

\section{Introduction}

The switched reluctance motor, SRM, is winning its own place in the electric drive market due to its simple and rugged construction, low expected manufacturing cost, fault tolerance capability, high efficiency and high torque to inertia ratio. Despite these advantages the SRM has some drawbacks: it requires an electronic control and shaft position sensor, a huge capacitor is needed in the D.C. link and the double salient structure causes noise and torque ripple. In variable speed applications the SRM is operated in one of the three control modes: current mode, voltage mode and single pulse mode. In current control the average electromagnetic torque is determined by the following parameters: reference current, speed, D.C. voltage, turn-on angle $\theta_{\text {on }}$, and turnoff angle $\theta_{\text {off }}$, Fig.1. In many current-controlled SRM drives current reference is the main control signal and the firing angles, $\theta_{\text {on }}$ and $\theta_{\text {off }}$, are moved in steps as a function of the speed, the same commutation or firing angles being used for a wide speed range. Nevertheless, in some cases torque per ampere ratio, torque ripple or efficiency must be optimized, so the firing angles must be accurately selected.

In many industrial applications, such as pumps and fans, load requirements are slowly varying or even constant. In these kinds of drive it is advisable, and economically advantageous, to add an efficiency optimization block to the closed-loop speed control.

Several papers have reported on control methods for SRM performance optimization, and a complete summary of the main contributions on this issue is given in [1]. Nevertheless, it is important to emphasize the work on efficiency optimization in voltage-controlled SRM drives described in [2][3] and especially in currentcontrolled SRM drives presented in [4].

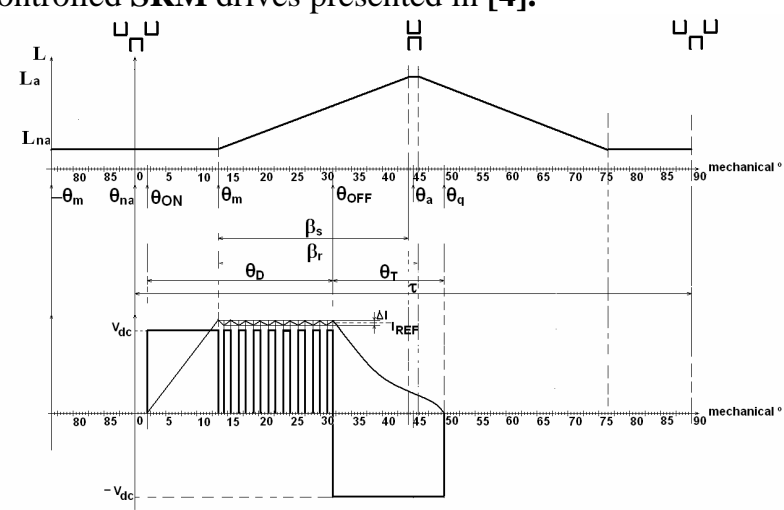

Fig. 1: Current control: Inductance, current and voltage waveforms with definition of firing angles.

In this paper a current-controlled SRM drive for variable speed applications with efficiency optimization is presented. Firing angles were computed online and then adjusted to minimize input power. In steady state operation the selection of firing angles was fine-tuned by means of an algorithm that minimizes the input power of the drive. A prototype SRM drive was tested and the experimental results show online efficiency improvement and good dynamic performance. Finally, the efficiency and electrical energy consumption was compared with that of a commercial vector-controlled induction motor drive, IM. 


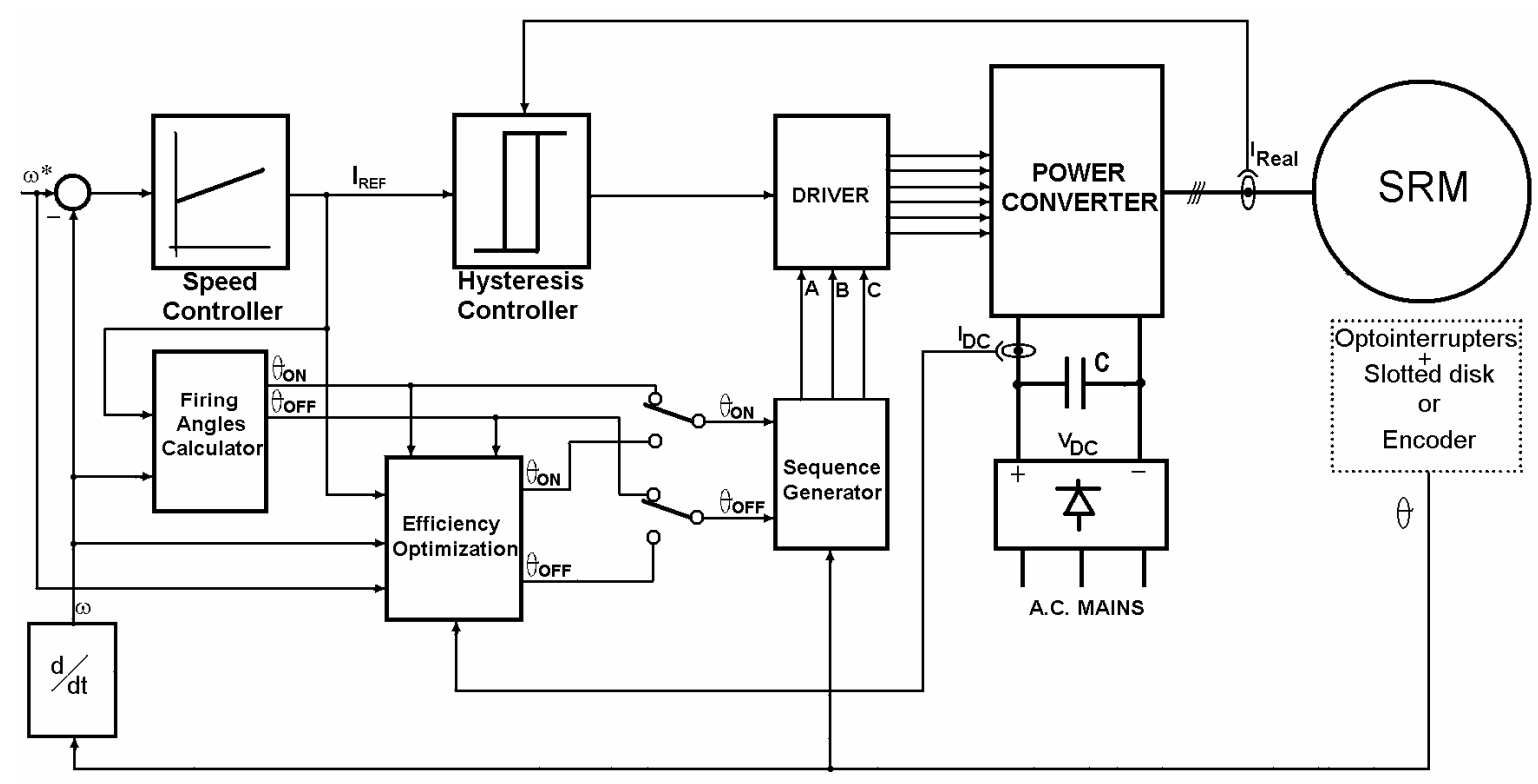

Fig. 2: Block diagram of an SRM drive.

\section{SRM drive description}

\subsection{General description}

A schematic block diagram of the variable speed SRM drive is shown in Fig. 2. The motor is a three-phase 6/4 SRM. The power converter is a half asymmetric bridge or classic converter, with two IGBTs and two fast diodes per phase. The rotor position is determined by means of an encoder or an ensemble formed by a slotted disk and three opto-interrupters placed inside the SRM. The speed controller, a proportional-integral (PI) controller, generates a current command based on the error between the reference speed and the motor speed. The current in the appropriate phase is regulated at the reference current by hysteresis control. The firing angle calculator computes turn-on and turn-off angles at every instant, taking into account the actual speed and the reference current. The drive includes an efficiency optimization block suitable for applications in which its use is economically advantageous. The control is fully digital and was implemented in a DSPACE ACE kit 1104 CLP that included a TMS320F240 DSP. The DSPACE ACE kit 1104 CLP is a rapid-prototyping tool that allows controllers to be designed in Simulink, a well-known simulation and prototyping environment for modeling dynamic systems. Once these controllers have been designed, the code is simply generated and loaded into a DSP for real-time control, thus allowing the control algorithm to be tested rapidly.

\section{2. Firing angle calculator}

At each instant, the firing angle calculator imposes the turn-on and turn-off angles. The proposed procedure does not require one to know the SRM magnetization curves but rather only the following parameters: speed, DC voltage, reference current and inductance in the aligned and non-aligned position. The turn-on angle is calculated by means of the following expression, which was first proposed by Bose [5]:

$\theta_{\mathrm{ON}}=\theta_{\mathrm{m}}-6 \frac{\mathrm{L}_{\mathrm{na}} \cdot \mathrm{N}}{\mathrm{V}_{\mathrm{dc}}} \mathrm{I}_{\mathrm{REF}}$

The turn-off angle is computed using the optimal turn-off angle in current control with the assumption of the piecewise linear gauge curve model, which is derived from the turn-off angle theory proposed by Gribble [6] using the following formula:

$\theta_{\mathrm{OFF}}=\theta_{\mathrm{a}}-\frac{\theta_{\mathrm{m}}}{2}\left(-\alpha+\sqrt{\alpha^{2}+\frac{24 \cdot \mathrm{I}_{\mathrm{REF}} \cdot(1-\mathrm{x}) \cdot \mathrm{N}}{\mathrm{R}_{\mathrm{ua}} \cdot \mathrm{V}_{\mathrm{dc}} \cdot \theta_{\mathrm{m}}}}\right)\left(^{\circ}\right)$

Where:

$\mathrm{R}_{\mathrm{a}}$ and $\mathrm{R}_{\mathrm{u}}$ are reciprocals of the aligned $\left(\mathrm{L}_{\mathrm{a}}\right)$ and unaligned $\left(\mathrm{L}_{\mathrm{na}}\right)$ inductances

$\mathrm{R}_{\text {ua }}=\mathrm{R}_{\mathrm{u}}-\mathrm{R}_{\mathrm{a}}$

$\alpha=\frac{\mathrm{R}_{\mathrm{a}}}{\mathrm{R}_{\text {ua }}}$

$\mathrm{N}$, speed (rpm)

$\mathrm{V}_{\mathrm{dc}}, \mathrm{DC}$ link voltage $(\mathrm{V})$

$\mathrm{x}$ is a constant (usually between $\frac{1}{\sqrt{2}}$ and $\frac{2}{3}$ )

\subsection{Efficiency Optimization block}

The efficiency optimization block works only when the drive is in steady state; in these conditions shaft torque and speed are constants, so mechanical power output is also constant [7]. Efficiency optimization therefore requires a minimization of the electrical power input, and if the DC voltage is constant maximum efficiency is obtained for the minimum input DC current. Thus, the 


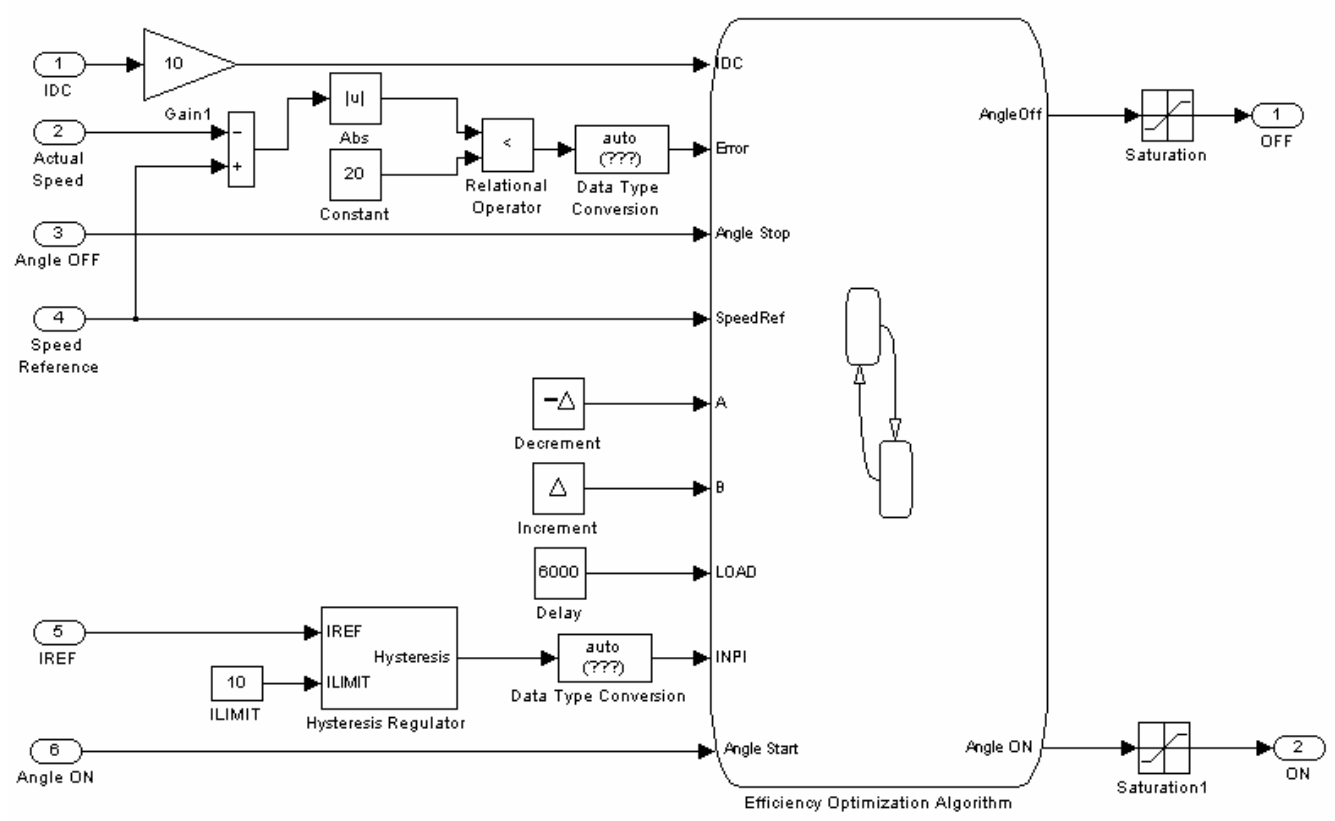

Fig.3: Diagram of Simulink implementation of the proposed efficiency optimization block.

proposed procedure requires the mean value of the input DC current to be known with high accuracy at every instant. The commutation angles, and especially the turnoff angle, are changed until the minimum input power or the input DC current is obtained. Fig. 3 shows the Simulink implementation of the proposed efficiency optimization block.

The initial values of the turn-on and turn-off angles for a given load are calculated by means of Expressions (1) and (2) respectively. Every change in the turn-off angle, under the assumption of a constant load, causes changes in the speed and therefore in the outside of the speed PI controller; that is, in the reference current. Thus, the minimum value of the input power is not reached until the reference current is stabilized at a constant value when the speed controller reaches saturation. A flowchart of the efficiency optimization algorithm is shown in Fig. 4. The algorithm is implemented in a Mealy state machine using Stateflow. Stateflow is a graphical design and development tool that works with Simulink. It visually models and simulates complex reactive state machine theory, flow diagram notations and statetransition diagrams all in the same diagram. It is important to note that the efficiency optimization is not fast and it takes some time to simultaneously achieve efficiency improvement and to maintain load requirements.Meanwhile, the turn-on angle is updated continuously by means of Equation (1). If there is a change in the load, commutation angles are initiated and the efficiency optimization process starts again.

\section{Comparative efficiency of SRM and IM drives}

In order to evaluate efficiency in the proposed SRM drive with the efficiency optimization block and to prove its suitability for applications that require energy savings,

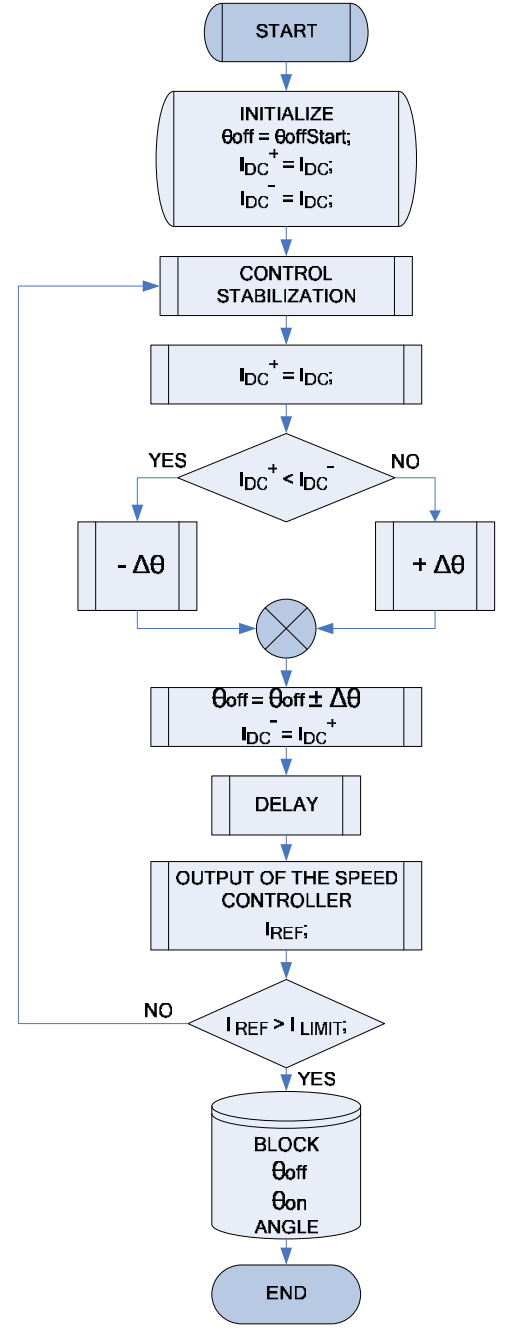

Fig. 4: Flowchart efficiency optimization algorithm. 

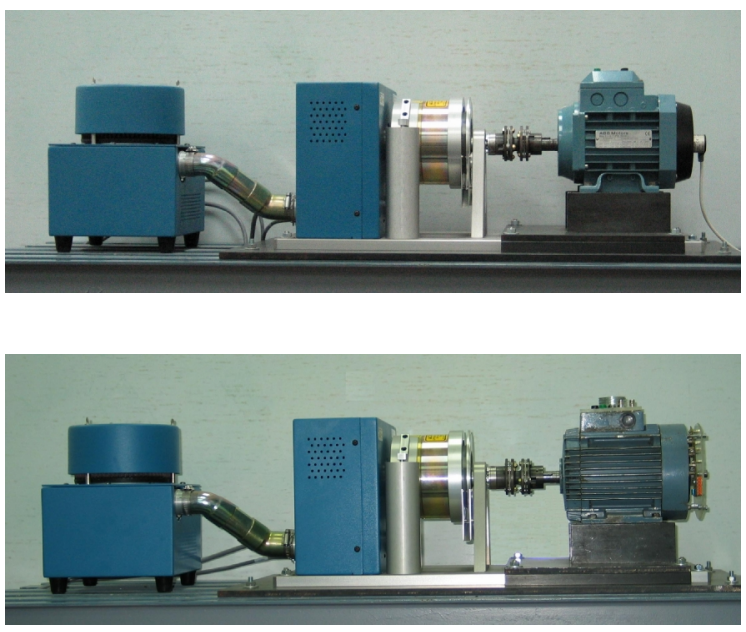

Fig. 5: Test bench with blower, hysteresis dynamometer and motor, IM up and SRM down.

TABLE I: Motor parameters.

\begin{tabular}{|l|l|l|}
\hline & \multicolumn{1}{|c|}{ IM } & \multicolumn{1}{c|}{ SRM } \\
\hline IEC frame & 80 & 80 \\
\hline Rated torque & $2.55 \mathrm{Nm}$ & $2.4 \mathrm{Nm}$ \\
\hline Rated power & $0.75 \mathrm{~kW}$ & $0.75 \mathrm{~kW}$ \\
\hline Nominal speed & $2830 \mathrm{rpm}$ & $3000 \mathrm{rpm}$ \\
\hline Voltage & $400 / 230 \mathrm{~V}$ & $300 \mathrm{~V}$ \\
\hline Aligned inductance & & $98 \mathrm{mH}$ \\
\hline Unaligned inductance & & $16 \mathrm{mH}$ \\
\hline Phase resistance & $8.4 \Omega$ & $1.6 \Omega$ \\
\hline Inertia & $0,00072 \mathrm{kgm}^{2}$ & $0,0007 \mathrm{kgm}^{2}$ \\
\hline
\end{tabular}

comparative tests with a commercial vector-controlled induction motor drive, IM, of the same size were carried out. The IM and SRM motor parameters are given in Table I. It should be noted that IM is not labeled as a high efficiency motor, and that SRM was not designed for efficiency optimization. Both drives were tested on a MAGTROL HD 710-8NA hysteresis dynamometer, Fig. 5. First of all, efficiency versus load torque was measured for both drives at nominal speed, $3000 \mathrm{rpm}$, Fig. 6. Then the two drives were forced to follow a duty cycle, with variable load at constant speed. The complete duty cycle, showing the different load steps (p.u.) and the speed against time for the SRM and IM motor drives is displayed in Fig.7. The completed duty cycle lasted 45 minutes, torque changes took 5 seconds, equivalent RMS torque was $1.65 \mathrm{Nm}$, the speed reference was maintained at $2000 \mathrm{rpm}$ in both drives and 1 p.u. $=2.4 \mathrm{Nm}$. The power and the energy in the A.C. mains as well as the mechanical power and torque were computed. Efficiencies in the different load steps are presented in
Table II for the IM and SRM motor drives, showing greater efficiency of the SRM drive in all load conditions and especially with low torque requirements. The total electrical energy consumption per cycle was $403 \mathrm{Wh}$ for the IM motor drives and $374 \mathrm{Wh}$ for the SRM motor drives. Therefore, if the cycle is repeated daily ten times, twenty two days per month, eleven months per year, the SRM choice amounts to an annual saving of $70.18 \mathrm{kWh}$.

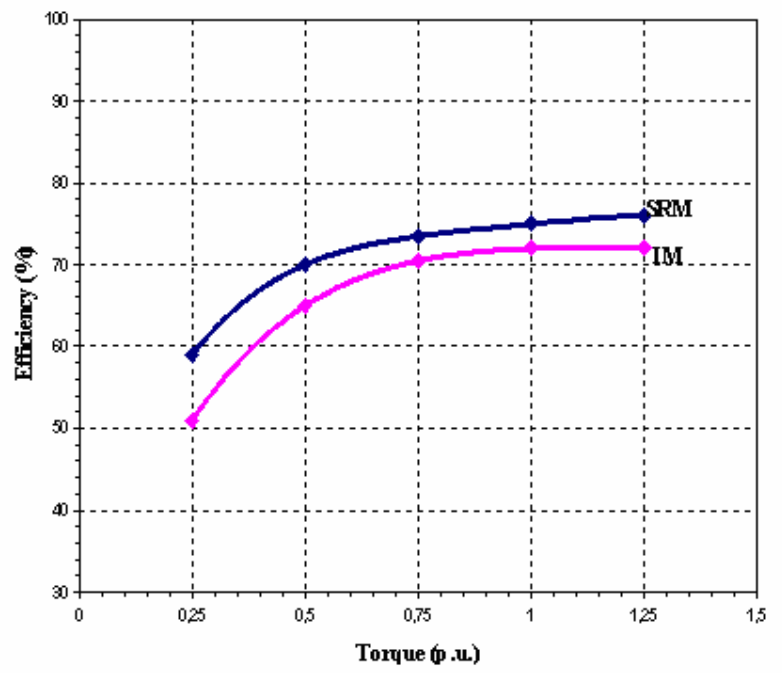

Fig. 6: Efficiency versus torque for the IM and SRM drives (motor and drive electronics being considered as a complete system). The speed reference in both drives was $3000 \mathrm{rpm}$.
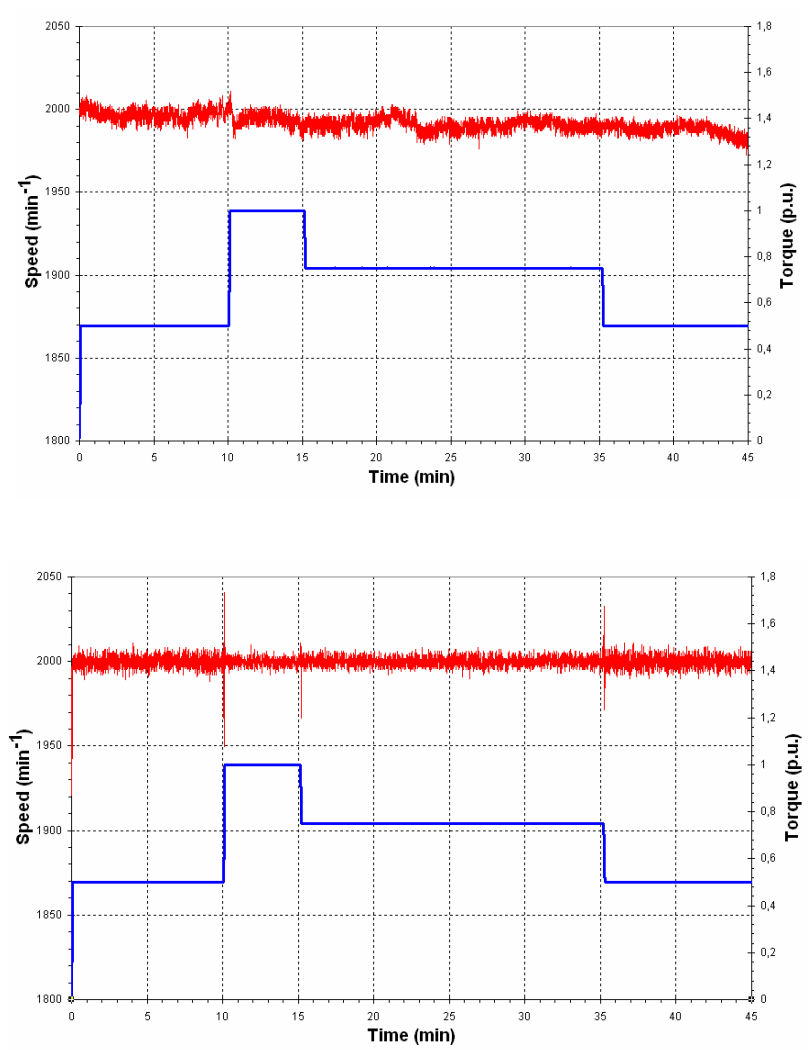

Fig.7: Load duty cycle (blue line) and speed (red line) versus time, IM up and SRM down. 
TABLE II. Efficiency comparison in the different load steps of the specified duty cycle.

\begin{tabular}{|c|c|c|c|}
\hline $\begin{array}{c}\text { Load } \\
\text { (p.u.) }\end{array}$ & Time (min) & $\begin{array}{c}\text { IM drive } \\
\text { efficiency (\%)* }\end{array}$ & $\begin{array}{c}\text { SRM drive } \\
\text { efficiency (\%)* }\end{array}$ \\
\hline $\mathbf{1 / 2}$ & 10 & 58 & 65 \\
\hline $\mathbf{1}$ & 5 & 68 & 69 \\
\hline $\mathbf{3 / 4}$ & 20 & 65 & 69 \\
\hline $\mathbf{1} / \mathbf{2}$ & 10 & 58 & 65 \\
\hline
\end{tabular}

* Efficiency is quoted from A.C. mains input to mechanical power output.

\section{Conclusions}

In this paper a current controlled SRM drive for variable speed applications with an efficiency optimization block is presented. A comparison of efficiency and electrical energy consumption with a commercial vector-controlled induction motor drive of the same size is reported. The results are clearly favorable to the SRM for all load conditions, and especially for light loads. Therefore, the proposed current-controlled SRM with an efficiency optimization block is especially suitable for applications that require slow varying loads and energy savings.

\section{References}

[1]. C. Mademlis and I. Kioskerides. Performance Optimization in Switched Reluctance Motor Drives with Online Commutation Angle Control. IEEE Transactions on Energy Conversion, Vol. 18, No. 3, pp. 448-456, September 2003.
[2]. P. C. Kjaer. High Performance Control of Switched Reluctance Motors. Ph.D. Thesis, University of Glasgow, July 1997.

[3] P. C. Kjaer, P. Nielsen, L. Andersen and F. Blaabjerg. A new energy optimizing control strategy for switched reluctance motors. IEEE Transactions on Industry Applications, Vol. 312, pp. 1088-1095, September/October 1995.

[4]. P. C. Kjaer, F. Blaabjerg, C. Cossar and T. J. E. Miller. Efficiency Optimization in Current Controlled Variable-Speed Switched Reluctance Motor Drives, European Power Electronics Conference, EPE, Seville, pp. 3741-3747, 1995.

[5]. B. K. Bose, T. J. E. Miller, P. M. Szczeesny, W. H. Bicknell. Microcomputer control of switched reluctance motors. IEEE Transactions Industry Applications, Vol. 22, No. 4, pp. 708-715, July/August 1985.

[6]. J. J. Gribble, P. C. Kjaer, T. J. E. Miller. Optimal commutation in average torque control of switched reluctance motors, IEE Proc. Electr. Power App., Vol. 146, No. 1, pp. 1-10, January 1999.

[7]. B.Blanqué, J.I. Perat, P.Andrada., M.Torrent. Improving efficiency in switched reluctance motor drives with online control of turn-on and turn-off angles. European Power Electronics Conference, EPE, Dresden 2005. 